\title{
Impact of Peer Evaluation in Reducing Social Loafing Tendency Among Students
}

\author{
Ferry Novliadi', Rika Eliana ${ }^{2}$ \\ Faculty ofPsychology \\ University of Sumatera Utara \\ Medan, Indonesia \\ Email: ferry.novliadi@usu.ac.id
}

\begin{abstract}
This research is focused on reducing social loafing. Peer evaluation is considered as one of an effective part in reducing social loafing in group-based tasks. Each member involved must be cautious about the contributions of other individuals who also participated in the same group. We conducted a study of 80 students attending lecturing in Metrology Department. They are divided into two groups: the experimental group, and the control group.Each group will be assigned a task by the lecturer. Both the experimental and the control group must submit their task by the following week. In addition to the experimental group, the students are also required to complete the peer evaluation. The peer evaluation results were then presented to the experimental group. The effectiveness of interventions can be seen by the decreasing of the score in Social Loafing Tendency in the experimental group.Applications of peer evaluation instrument could be the one strategy to reduce social loafing among students.
\end{abstract}

Keywords: group-based task; peer evaluation; social loafing

\section{INTRODUCTION}

In this research, we will analyze one of the determinants that make the application of groupbased learning activities in the classroom to be ineffective. Basically, learning activities in groups can be a positive thing to do. With a group, we can perform tasks that individually can't be done, but not everyone involved in the group contributes equally to achieve group goals. Often not all members of the group uphold the values and ethics of cooperation. Some members of the group even reduce their effort and hope others to do the job. When individuals reduce their effort in group activities then it will certainly make other members be the victims. This condition will certainly make group learning ineffective. In the social psychology, the individual's tendency to reduce the effort or contribution he should be able to give when he works in groups, compared to the effort he can do when working independently is called Social Loafing (Karau\& Williams, 1993; Latané, Williams, \& Harkins, 1979). Many studies have focused on the contextual aspect of social idleness. Individuals also tend to engage in social idleness when they assess that their effort is not essential for group performance (e.g., Price, Harrison, \& Gavin, 2006). Social idleness also often arises when the individual perceives the absence of contingency (reward or punishment) between the effort he spends and the results he gets (e.g., Shepperd\& Taylor, 1999). In short, social idleness is most likely to occur if individual efforts seem to 'drown' with the group, so the uniqueness of individual efforts cannot be identified. According to research conducted by Ringelmann (1913), one will reduce its performance when in a large group. Hogg (2002) gives two suggestions why people do social loafing. First coordination Loss is a condition where the group is too crowded, interference occurs and someone withdraws his effort compared to others and does not expend his potential to the maximum. While the second is the motivation loss when the individual has a little motivation and they did not try hard. The problem according to Ying (2004) there are individuals who do have the nature to reduce effort every time they work in agroup, but some are improving the results of their work in agroup. In his research Ying proposed Social Loafing Tendency Questionnaire (SLTQ), a tool that eventually used as a reference to be able to detect someone who is lazy when they have to work in groups. But with all the shortcomings that exist, working in groups cannot be avoided so the thing that should be done is to make all members involved in the group work effectively, so social loafing would not happen. There are several ways that have been done to reduce social loafing, one of them is to identify individual's output and compare the individual's output and output of its peers (Harkins and Jackson, 1985). According to Harkins and Syzmanski (1987), there are two things from theevaluation that can reduce social 
loafing,the first one is output calculations. That means the output of each individual must be calculated. Then the second one is there must be a standard that can be compared to the output. So, the calculated output can be compared to the other group members in the group. Individual output can be measured by the supervisors, lecturers and members of the group itself, although it is undented to be biased when judging with no clear reference. Kelley (2015) in his research on engineering students found that peer evaluation was effective in increasing group effectiveness. Measurement of peer evaluation is divided into two parts: first the participants are given an assessment based on the quality category, the quantity of participation, the time was given, the level of work. The second participant evaluates the percentage of contribution he/she provides and the other members of the group settlement. Kelley assesses the task of a project design so that individual contributions are measurable in completing the design. Referring to what Kelley did,we did the experimentation more or less the same whether this can apply to students whose work is related to the discussion of learning materials. Our assumption is that when one's contribution to the execution of a task is not measurably clear, it will be more difficult to evaluate someone and this will affect social loafing.

\section{RESEARCH METHODS}

\section{A. Types of Research}

This research is a quasi-experimental research. With pretest-posttest control group design to determine the effect of certain variables on other variables by manipulating independent variable through a treatment.

\section{B. Participant}

This research used a sample of 80 students of the Ethical of Profession class from Metrology Departement in Faculty of Mathematics and Natural Sciences, University of Sumatera Utara, Medan. They are divided into two classes,class A, and class B, each has 40 students. Each class is subdivided into several task groups of 4-6 people in a group. The data retrieval time is in September 2017 (4 weeks or 4 meetings) and 4th week is the final examination week of 4 th task collection.

\section{Measuring instrument}

Social idleness tendency is measured by using the translational version of the Social Loafing
Tendency Questionnaire (Ying et al., 2014), translated by Zahra (2015). The Social Loafing Tendency Questionnaire(SLTQ) has 7 reliable items (e.g. "In my team/group, my role is often not so important","In my team/group, my contribution is often less than it should be", $\alpha=$ .88).

\section{Procedure}

At the beginning of classroom activity, thestudent is given a questionnaire to be filled, the questionnaire is Social Loafing Tendency Questionnaire (SLTQ). The questionnaire begins with a brief description of the research to be conducted along with the informed consent. After giving the questionnaires then the lecturer divided the task group. Next week at the time when theschedule was given, the assignment was collected, and each student was given a peer evaluation sheet, where they began to evaluate their own contributions including the contribution of their friend's work on the tasks that have been collected.

The peer evaluation sheets were collected and then counted manually. At the end of classroom activity, lecturer gave another group assignments for the next week. A week later the peer evaluation results were read by the lecturers in class A in which each group was discussing with the lecturer after the completion of teaching and they were given an assignment for the next week in each group. In each group, he gave feedback on what percentage of contributions the group members gave to the task at last week. Any member who was not satisfied with the results of a peer review may give reasons or arguments against their results. And it went so on until the whole group in class A thoroughly given feedback. In class B, feedback was not given because it was a control group. Before starting the activity,we conducted experiment 1 (tryout) manually to see the results and evaluate the measuring tool that will be used.

\section{RESULT AND DISCUSSION}

The data used were derived from the results of SLTQ of group 1 (experimental group/class A) and group 2 (control group/class B). Then we saw whether there wasa significant difference of social loafing tendency's score in group 1 before and after the treatment. 
By using paired sample-test, it can be seen that there was a difference of social loafing tendency's mean score among students in group 1 before and after treatment (Sig $=0,03$; $p$ value $<0,05$ ) with mean $=1,071$ with positive value, which mean there was a decreasemen tof 1.07 .

\section{Group Statistics}

\begin{tabular}{|l|l|l|l|l|l|}
\hline & $\begin{array}{l}\text { Grou } \\
\mathrm{p}\end{array}$ & $\mathrm{N}$ & Mean & $\begin{array}{l}\text { Std. } \\
\text { Deviatio } \\
\mathrm{n}\end{array}$ & $\begin{array}{l}\text { Std. } \\
\text { ErrorMe } \\
\text { an }\end{array}$ \\
\hline \multirow{2}{*}{ Value } & 1 & 28 & 10,50 & 2,411 &, 456 \\
\cline { 2 - 6 } & 2 & 20 & 11,45 & 2,259 &, 505 \\
\hline
\end{tabular}

Actually from the two treatments given to both groups, experiment and control group, there were differences. As we could see from the table above, there was a difference of 0.95 point between Mean score of Group 1 and Group 2. The experimental group (Group 1) has a smaller mean score than the control group (Group 2).

Although there was no significant difference, but if we lookat the comparison of mean score between experimental group and control group, the treatment given to the experimental group had an impact in reducing social loafing tendency among students. From comparison based on mean score above, we could see that there was a decrease ment of social loafing tendency in the experimental group, where as in the control group there was a slight in creasement of social loafing tendency.

\section{CONCLUSION}

The conclusion of this paper was giventhat:

1. There was a difference of social loafing tendency's mean score among students in experimental group before and after treatment by using Peer Evaluation Instrument.

2. Usage of Peer Evaluation Instrument in classroom with group based task activity had an impact in reducing social loafing tendency among students.

\section{REFERENCES}

Harkins, S. G., \& Jackson, J. M. (1987).The role of evaluation ineliminating social loafing. Personality and Social Psychology Bulletin, Vol.11(4), 457-465
It means the treatment given to the experimental

1 group has impact in reducing social loafing tendency among students.

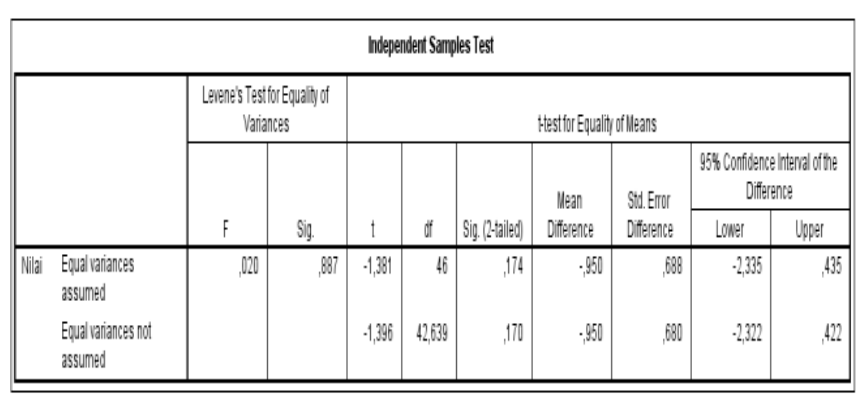

However, when viewed from the results in group 1 and group 2, it was found that sig $=0.174$ ( $p>0.05)$. Its how ed that there was no significant difference between group 1 which had been treated with group 2 which were not treated on the second measure ment of social loafing tendency.

Karau, S. J., \& Williams, K. D. (1993). Social loafing: a meta-analytic review and theoretical integration. Journal of Personality and Social Psychology, 65, 681-706.

Kelley, D. S. (2015). Peer Evaluation within a Team Design Project. Proceedings of the Mid-year Conference of the Engineering Design Graphics Division of the American Society for Engineering Education, USA.

Price, K. H., Harrison, D. A. \&Gavin J. H. (2006). Withholding inputs in team contexts: member composition, interaction processes, evaluation structure, and social loafing. Journal of Applied Psychology, 91, 1375-1384

Michael, A.,Hogg\&Vaughan, G. M.(2002). social psychology, ThirdEdition. Pearson Prentice-Hall

Shepperd, J. A., \&Taylor, K. M. (1999), SocialLoafingandExpectancy-

ValueTheory.

PersonalityandSocialPsychologyBulletin, 25(9), 1147-1158.

Szymanski, K., \&Harkins, S. G. (1987). Socialloafingandself-evaluationwith a socialstandard. 
JournalofPersonalityandSocialPsychology, 53(5), 891-897.

Ying, X., Li, H., Jiang, S., Peng, F., \& Lin, Z. (2014).

Group laziness: The effect of social loafing on group performance. Social Behavior and Personality: An international journal, 42, 465-472 